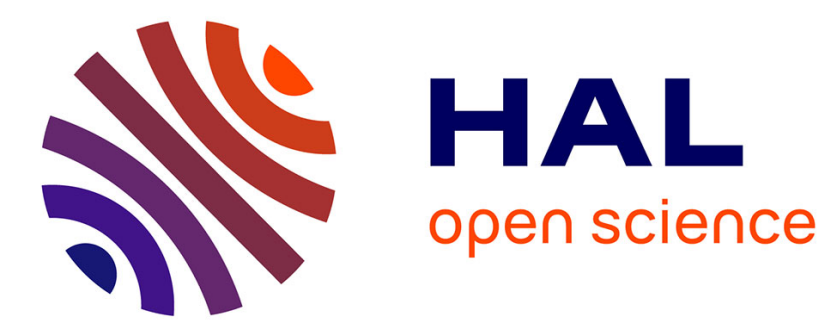

\title{
C'était au temps du grand confinement
}

\author{
Patrick Boucheron
}

\section{To cite this version:}

Patrick Boucheron. C'était au temps du grand confinement. Revue Esprit, 2020, Le virus dans la cité, 2020 (5), pp.131-136. 10.3917/espri.2005.0131 . hal-03264902

\section{HAL Id: hal-03264902 \\ https://hal.science/hal-03264902}

Submitted on 18 Jun 2021

HAL is a multi-disciplinary open access archive for the deposit and dissemination of scientific research documents, whether they are published or not. The documents may come from teaching and research institutions in France or abroad, or from public or private research centers.
L'archive ouverte pluridisciplinaire HAL, est destinée au dépôt et à la diffusion de documents scientifiques de niveau recherche, publiés ou non, émanant des établissements d'enseignement et de recherche français ou étrangers, des laboratoires publics ou privés. 


\section{C’ÉTAIT AU TEMPS DU GRAND CONFINEMENT}

\section{Patrick Boucheron}

Éditions Esprit | «sprit »

2020/5 Mai | pages 131 à 136

ISSN 0014-0759

ISBN 9782372341301

Article disponible en ligne à l'adresse :

https://www.cairn.info/revue-esprit-2020-5-page-131.htm

Distribution électronique Cairn.info pour Éditions Esprit.

(C) Éditions Esprit. Tous droits réservés pour tous pays.

La reproduction ou représentation de cet article, notamment par photocopie, n'est autorisée que dans les limites des conditions générales d'utilisation du site ou, le cas échéant, des conditions générales de la licence souscrite par votre établissement. Toute autre reproduction ou représentation, en tout ou partie, sous quelque forme et de quelque manière que ce soit, est interdite sauf accord préalable et écrit de l'éditeur, en dehors des cas prévus par la législation en vigueur en France. Il est précisé que son stockage dans une base de données est également interdit. 


\section{C'était au temps du grand confinement}

\section{Patrick Boucheron}

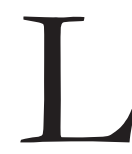

e temps viendra où celui que nous vivons trouvera à se dire. Et lorsqu'il inventera le moyen de se voir en face, ce temps enfin venu se mirera, comme toujours, dans le nom d'une époque passée. Mais j'ai tort de parler ainsi. «Le temps s'en va, le temps s'en va Madame / Las! le temps non, mais nous nous en allons ${ }^{1}$ ». Et puisque le temps, de lui-même, ne fait rien à l'affaire, quelqu'un, ou quelque chose, le désignera d'un nom qui, de manière insidieuse ou éclatante, finira par s'imposer. Le 14 avril 2020, sur le blog du Fonds monétaire international, un chrononyme a fait son apparition, fantomatique comme toutes les apparitions. On le doit à Gita Gopinath, professeure indo-américaine à Harvard, signant un post intitulé : The Great Lockdown: Worst Economic Downturn Since the Great Depression. C'est une femme, directrice du département de la recherche au FMI, première cheffe économiste de l'histoire de cette institution : le fait n'est sans doute pas sans importance si l'on veut bien admettre que l'épidémie a cueilli un monde que la révolution des femmes était en train de reformuler en profondeur. Avec cette force de frappe dont dispose la langue anglaise dès lors qu'il s'agit de construire des évidences, c'est-à-dire de faire croire que quelque chose existait déjà au moment même où on l'impose (il faudrait la subtilité d'un Louis Marin pour décrire la manière qu'à aujourd'hui cette langue dominante de l'expertise économique mondiale pour marteler les esprits comme l'on frappe monnaie), «Great Lockdown 2020 » prend déjà rang dans les graphiques, à la parade avec « Global Financial Crisis 2009 » et «Great

1 - Pierre de Ronsard, « Je vous envoie un bouquet ", Continuation des Amours, XXXV, 1555. 
Depression $1929 »-$ puisque c'est évidemment à ce précédent qu’il fait de l'œil.

Sauf que traduit en français par « Grand Confinement», le chrononyme débutant regarde vers une autre histoire, découpant différemment le temps - ou plus précisément, le politisant d'une autre manière, en un ciel plus chargé encore puisque s'y attardent les sombres nuées du théologicopolitique. S'écrivant, l'histoire ne peut s'exonérer de cette connaissance par assonance que porte la langue elle-même, allant son propre train, à coup d'analogies. Celle qui vient à l'esprit renvoie inévitablement au «grand renfermement» par lequel Michel Foucault pensait la manière dont l'ordre de la raison, en enfermant les exclus, capturait l'extérieur. Dans son Histoire de la folie à l'áge classique, Michel Foucault en trouvait, c'est bien connu, sinon le précédent du moins le paradigme dans la fondation de l'hôpital général de 1656 destiné aux pauvres, aux vagabonds, aux délinquants et aux insensés. Recluse désormais, arrachée à cette "liberté imaginaire qui la faisait foisonner encore sur le ciel de la Renaissance », la folie internée est soumise " aux règles de la morale et à leurs nuits monotones ${ }^{2}$ ».

Cinq ans plus tôt, en 1651 donc, Thomas Hobbes décrivait dans le Léviathan une manière de composer un ordre politique par la crainte d'un état de guerre qui était moins le scénario d'épouvante des batailles du passé que «le théatre des représentations échangées », selon l'expression de Michel Foucault lui-même ${ }^{3}$. Une fois de plus, nous y sommes. Face aux

Face aux hantises

du biopouvoir,

nous voici à

nouveau devant

le frontispice du

Léviathan.

hantises du biopouvoir, nous voici à nouveau devant le frontispice du Léviathan, affrontant le regard du monstre, soumis à cet événement visuel qui immobilise le cours de la pensée, dans l'ivresse de sa propre nettetét. Voici donc apparaitre le spectre, the ghost. On le voit nous regarder. Il n'est d'ailleurs rien d'autre que cela : une agrégation d'obéissances, l'agglutinement des solitudes craintives, ce rassemblement de la peur qu'il inspire. L'analyse iconographique qu'en propose Carlo Ginzburg donne corps à cette expression : remplir de crainte. "Le Léviathan, création artificielle, se

2 - Michel Foucault, Histoire de la folie à l'âge classique, Paris, Gallimard, 1961, p. 91.

3 - M. Foucault, "Il faut défendre la société ». Cours au Collège de France. 1976, Paris, EHEss/ Gallimard/Seuil, 1997, p. 80.

4 - Horst Bredekamp, Stratégies visuelles de Thomas Hobbes. Le Léviathan, archétype de l'État moderne, trad. par Denise Modigliani, Paris, Éditions de la Maison des sciences de l'homme, 2003. 
dresse face à ceux qui l'ont créépar leurpacte - ceux dont il estfait - comme un objet qui remplit de crainte ${ }^{5}$. » Mais d'où viennent-ils, tous ceux qui forment le corps politique de ce «dieu mortel» et s'y enferment à leur corps défendant? D’en bas : vous le voyez bien, la ville est dépeuplée. Nulle âme qui vive, l'intraitable géométrie des rues désertes coupant net toute possibilité d'urbanité. Et si l'on regarde de plus près, face à la cathédrale, voici deux minuscules silhouettes, deux profils qui se détachent comme des pattes de mouche sur la noirceur gravée. Ils portent le masque à bec caractéristique des médecins de peste. Ils veillent sur la ville morte, c'est-à-dire qu'ils la surveillent davantage qu'ils ne la soignent. Se tenant au seuil exact entre santé et souveraineté, ces ombres épidémiques désignent le bord de l'image où la multitude dissoute devient proprement irreprésentable ${ }^{6}$.

L'aurore fantomatique du Léviathan qui surgit à l'horizon, son corps grumeleux composé des regards qu'il suscite, aurait donc siphonné la ville de ses habitants, comme un évier inverse qui se vide au ciel ? J'ai longtemps rêvé, face à l'image, cet événement impossible. Je le faisais avec les moyens du bord, sans nécessairement faire œuvre d'historien, mais en me laissant guider par ces associations d'idées et ces dissociations d'images qui trament la raison des songes. J'usais pour cela, secrètement, d'un souvenir que je n'avais pas : celui que Louis Marin avait rapporté d'un voyage au Japon, et qu'il avait décrit dans un texte bref et mystérieux intitulé «Le bambou à bascule ${ }^{7} »$. Je le lisais sans le comprendre, pressentant seulement que se disait là, avec l'autorité lointaine mais irrécusable que confère la nature poétique du langage - l'exact contraire, on l'aura compris, du pouvoir cinglant et supposé définitif de la langue des experts - quelque chose d'essentiel sur la nature même d'un événement en histoire, quelque chose qui devait, si on y prêtait l'oreille, ridiculiser d'un coup toute prétention historienne à qualifier le temps qui vient au moment même où il advient, puisqu'il n'adviendra vraiment

5-Carlo Ginzburg, Peur révérence terreur. Quatre essais d'iconographie politique, trad. par Martin Rueff, Dijon, Les Presses du réel, 2013, p. 28.

6 - Voir sur ce point Giorgio Agamben, La Guerre civile. Pour une théorie politique de la stasis, trad. par Joël Gayraud, Paris, Points, 2015, p. 52-53, qui reprend les analyses de Francesca Falk, Eine gestische Geschichte der Grenze, Munich, Fink, 2011.

7 - Louis Marin, "Le bambou à bascule ", Traverses, 38-39, 1986 ("Le Japon et ses fictions »), p. 66-69, repris dans L. Marin, Lectures traversières, Paris, Albin Michel, 1992, p. 263-267. 
qu'une fois pleinement advenu, c'est-à-dire dans ses répliques et ses recommencements.

Voici donc l'objet du délit. C'est une tige de bambou d'un mètre environ, soigneusement évidée; l'une de ses extrémités est fermée à la base, l'autre est taillée en biseau. Cette dernière est placée sous un mince filet d'eau qui la remplit lentement, jusqu'à ce que la tige bascule sur son axe, vienne se vider dans le ruisseau en frappant une pierre d'un coup sec. Clac. Ou plutôt : clac, clac. Car le coup se dédouble, le second étant plus léger, flûté. Voici ce qui arrive, voici ce qui ne peut qu'arriver, à intervalle plus ou moins régulier, inévitablement. Le renversement est mécanique, mais c'est cette infime variation qui aiguise l'attente jusqu'au vertige. L'histoire est vide d'événements, mais grossit lentement, en attente de l'instant du renversement, instant toujours trop bref, toujours répété, toujours insaisissable. On dit qu'en 1672, Ishikawa Jōzan mourut de contemplation devant son bambou à bascule, que son intendant avait placé à la lisière de son jardin pour éloigner les daims et les sangliers : "Ce qui capte l'attention, ce qui attire la pensée, ce qui fascine, ce n'est pas tant le dispositif du bambou à bascule que ce fil du temps, ce mince fil du temps, aussi mince, aussi clair, aussi vide que le filet d'eau coulant dans la tige, coupé à intervalles presque réguliers par une catastrophe sonore et inexorablement repris dans l'attente sans surprise de l'autre, presque semblable, qui la suivra ${ }^{8}$."

Et puis il y a autre chose, plus mystérieux encore. Un très ancien manuscrit raconte, dit Louis Marin, qu'un peuple vivait jadis sur le bord circulaire d'un immense lac, venant alimenter l'eau d'un fleuve coulant d'une brèche ouverte dans la chaîne de montagnes qui bornait son horizon (sur le frontispice du Léviathan aussi, une chaîne de montagnes borne l'horizon). Mais l'ancienne cosmogonie disait que ce fleuve prenait sa source dans le ciel, comme un don des dieux, et qu'à la suite de je ne sais quel crime, ce peuple « qui avait atteint un niveau de puissance et de richesse inimaginable » fut englouti dans une catastrophe, un déluge à l'envers venu non du ciel mais des profondeurs abyssales du lac. L'assemblée des sages poètes et des secrets ermites avait remarqué que, depuis des siècles, imperceptiblement, l'eau montait. Mais le roi ne l'avait pas écoutée. Pire : cela faisait des années qu'il falsifiait les rapports chiffrés du Haut Conseil des eaux calmes terrestres. Il y eut un jour où le fleuve du ciel ne coulait 
plus de sa brèche que par un mince filet, l'eau clapotait au ras des quais de marbre et des débarcadères d'onyx, puis d'un coup, tout se renversa, comme le bambou qui bascule, qui décolle et qui se vide, clac, l'eau du lac se déversa dans le ciel, précipitant avec elle la cité orgueilleuse. Après un léger rebond, clac, clac, tout revint à sa place. Tout? Non. Louis Marin écrit : "Toutes les choses reprirent leur place, moins les hommes". "

Où sont les hommes ? En relisant ce texte aujourd'hui, en comprenant désormais qu'il décrit moins une «catastrophe d'origine » que la possibilité d'un désastre terminal, je saisis peut-être mieux le lent dévidement de l'événement en cours, mais de ce fait même, je perds le fil qui le reliait secrètement, je veux dire pour moi seul, à l'image où s'immobilise la pensée de Thomas Hobbes, en façade du Léviathan. Peut-être que les silhouettes ombreuses qui ont rejoint le corps vaporeux de cette grosse baudruche ne sont que des avatars, la nuée formant le cloud, ce dernier n'étant qu'un fantôme formé de fantômes. Comme une bibliothèque où manqueraient tous les livres. Ce que l'on verrait alors, cette myriade de regards dans le ventre du pouvoir qui, littéralement, les tient à l'œil, serait bien un fantôme, mais au sens des salles de lecture où « tout volume manquant suppose la présence d'une fiche fantôme qui porte un nom, celui de l'emprunteur ${ }^{10} »$. Les livres manquent, les hommes n'y sont pas, sans doute parce qu'ils sont toujours dans leurs maisons, mais on ne les voit plus, et eux-mêmes ne se voient plus, sinon par l'intermédiaire de leurs avatars respectifs. La ville n'est pas dépeuplée, elle est juste désolée. Chacun est bien chez soi, à sa place, mais rien ne bouge, et tout est replié.

Certains livres me manquent, mais peu importe: on fait avec ce que l'on a. On rassemble, on relit et on relie. C'est du moins ce qu'il conviendrait de faire aujourd'hui. Le plus souvent, on n'y parvient pas. Parfois au contraire, c'est sans effort : l'événement, et c'est d'ailleurs à cela qu'on le reconnait, se charge pour nous de relire et de relier. On regarde une vieille image que l'on pensait connaître, sur laquelle et par laquelle on avait écrit, rêvé, parlé, aimé - pour moi, par exemple, la cité désertée et stérile, ensauvagée et injuste peinte à fresque par Ambrogio Lorenzetti en 1338 sur la paroi funeste du Palazzo Pubblico de Sienne: «toutes les boutiques sont fermées, sauf celle de l'armurier. La troupe armée s'est déversée partout dans 
les rues, comme un fleuve débordant de son lit. Elle rôde, déscuvrée et menaçante ${ }^{11}$ ». On la regarde à nouveau, et avec surprise on ne la reconnait plus tout à fait : elle n'est plus la même. Mais elle est encore plus ressemblante. Pour le reste, inutile de forcer. Le temps viendra où l'on trouvera les mots pour le dire. Ceux qui nous accompagnent aujourd'hui sont incertains et lointains. Depuis un passé ancien, ils viennent à notre rencontre. Ils ne parlent pas haut et fort, ils ne disent rien de définitif. Ils attendent le moment de laisser place à l'écriture, puisque María Zambrano nous a appris qu'" on écrit pour regagner du terrain sur la déroute continuelle d'avoir longuement parlé 12 ». Et quitte à le dire en langue anglaise, autant se souvenir de celle de Shakespeare, au temps où avec Le Roi Lear la folie «se débattait en plein jour ${ }^{13} \gg$ :

The weight of this sad time we must obey;

Speak. what we feel, not what we ought to say.

«Au poids de ce sombre temps, il nous faut nous soumettre.

Dire ce que nous sentons, non ce que nous devrions dire ${ }^{14}$.»

11 - Patrick Boucheron, Conjurer la peur. Sienne, 1338. Essai sur la force politique des images, Paris, Seuil, 2013, p. 120.

12 - María Zambrano, L'Inspiration continue. Essais pour les perplexes, trad. par Jean-Marc Sourdillon et Jean-Maurice Teurlay, Grenoble, Jérôme Millon, 2006, p. 20.

13 - M. Foucault, Histoire de la folie, op. cit., p. 91.

14-Shakespeare, Le Roi Lear, trad. par Armand Robin, Paris, Gallimard, 2014, V, 3, 323-324. La dernière réplique d'Edgar dans Le Roi Lear doit être lue jusqu’à sa didascalie finale : « Ils sortent tous, au son d'une marche funèbre " (Exeunt, with a dead march), comme le rappelle si justement Wajdi Mouawad (« Journal de confinement ", vendredi 10 avril 2020, www.colline.fr). 